\title{
An alternative approach to intragastric balloon
}

\section{retrieval}

Placement of an intragastric balloon is a nonsurgical treatment for weight loss [1, 2]. Balloon retrieval can be difficult, however: forcing or persisting can cause perforation or esophageal laceration, as well as extending the anesthesia time [3-5].

The patient should be on a liquid diet for 2 days, drinking diet coke, which cleans away any residual food around the balloon, and then only water for the last 12-24 hours; the patient should fast for the final 12 hours.

The treatment uses the BIB system (Apollo Endosurgery, Austin, Texas, USA), which consists of a wire grasper removal instrument and needle aspirator. An aspiration catheter (Halyard Health, Alpharetta, Georgia, USA), Raptor grasper device (US Endoscopy, Mentor, Ohio, USA), and vegetable oil may also be used ( $\bullet$ Video 1 ). With the patient under general anesthesia, a gastroscope is used to aspirate the gastric content. The gastric lumen is then deflated in order to prevent the balloon from moving during puncture and aspiration. The puncture needle is held in the needle aspirator, with its sharp end inside the catheter. The needle is then pushed inside the balloon to puncture it, and then removed leaving the catheter inside. The catheter is connected to a vacuum drainage device, and the entire contents of the balloon are aspirated, resulting in the balloon's collapse.

To remove the balloon, the wire grasper removal instrument is inserted and grasps the superior part of the balloon, which has collapsed into folds. Slowly and gradually the endoscope is pulled back into the esophagus. Antispasmodic medication can be administered to relax the esophageal muscles.

After reaching the gullet, the balloon is slowly removed from the mouth of the patient.

An alternative approach to balloon retrieval involves spraying vegetable oil over the balloon and throughout the esopha- gus. This method facilitates retrieval by making it easier to slide the balloon over the cardia and upper esophageal sphincter, and helps to avoid injury to the esophagus. A catheter can be used to spray $10 \mathrm{~mL}$ of vegetable oil over the balloon, esophagus, and gastric cardia. A Raptor grasper device is then used to grab the balloon.

Knowledge and use of the vegetable oil technique can reduce the risk of complications in cases of difficult balloon retrieval.

Endoscopy_UCTN_Code_TTT_1AQ_2AH

Competing interests: None

\section{Galvao Neto ${ }^{1}$, Josemberg Campos ${ }^{2}$, Alvaro Ferraz ${ }^{2}$, Ricardo Dib ${ }^{3}$, Flavio Ferreira $^{2}$, Rena Moon ${ }^{4}$, Andre Teixeira ${ }^{4}$}

${ }^{1}$ Endoscopy Department, Gastro Obeso

Center, Hospital Nove de Julho, Sao Paulo, Brazil

2 Surgery Department, Pernambuco Federal University Hospital, Pernambuco, Brazil

${ }^{3}$ Endoscopy Department, School of Medicine, University of Sao Paulo, Sao Paulo, Brazil

${ }^{4}$ Surgery Department, Orlando Regional Medical Center, Orlando Health, Orlando, Florida, United States

\section{References}

1 Kumar N. Endoscopic therapy for weight loss: gastroplasty duodenal sleeves, intragastric balloons, and aspiration. World J Gastrointest Endosc 2015; 7: 847-859

2 Carvalho G, Barros CB, Moraes CE et al. The use of an improved intragastric balloon technique to reduce weight in pre-obese patients - preliminary results. Obes Surg 2011; 21: 924-927

3 De Castro MD, Morales MJ, Martinez-Olmos $M A$ et al. Safety and effectiveness of gastric balloons associated with hypocaloric diet for the treatment of obesity. Rev Esp Enferm Dig 2013; 105: 529-536

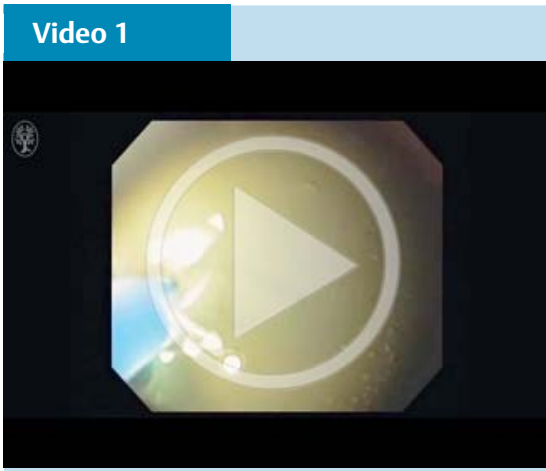

Intragastric balloon retrieval. The procedure uses the BIB system (Apollo Endosurgery, Austin, Texas, USA), which consists of a wire grasper removal instrument and needle aspirator. An alternative approach uses the needle aspirator, the Raptor grasper device, and vegetable oil to ease removal of the balloon and avoid injury to the esophagus.

4 Del Pozo P, Flores B, Liron R et al. Gastric perforation during removal of an intragastric balloon. Obes Surg 2009; 19: 1195-1196

5 Nijhof HW, Steenvoorde P, Tollenaar RA. Perforation of the esophagus caused by the insertion of an intragastric balloon for the treatment of obesity. Obes Surg 2006; 16: $667-670$

Bibliography

DOI http://dx.doi.org/

10.1055/s-0042-101856

Endoscopy 2016; 48: E73

(c) Georg Thieme Verlag KG

Stuttgart · New York

ISSN 0013-726X

Corresponding author

Josemberg Campos, MD, PhD

General and Digestive Surgery Unit

Pernambuco Federal University Hospital

50610-160 Recife Pernambuco

Brazil

Fax: +55-81-34414460

josembergcampos@gmail.com 